\title{
Giant Nonparasitic Splenic Cyst Managed by Minilaparoscopy
}

\author{
Gustavo Lopes de Carvalho, MD, PhD, Diego Laurentino Lima, MD, Frederico Wagner Silva, MD, \\ Gustavo Henrique Belarmino de Góes \\ Department of General Surgery, University of Pernambuco (UPE), Faculty of Medical Sciences, Recife, Brazil \\ (Dr. Carvalho, and Mr. GÓES) and Clinica Cirurgica Videolaparoscopica, Recife, Brazil (Dr. Carvalho). \\ State Servers Hospital, Recife, Brazil (Dr. Lima). \\ Minimally Invasive Surgery Program, Getulio Vargas Hospital, Recife, Brazil (Dr. Silva).
}

\begin{abstract}
Introduction: Nonparasitic splenic cyst (NPSC) is a rare disease of the spleen and is categorized as a true or pseudocyst. Traditionally, the management of NPSC is partial or total splenectomy by laparotomy; however, minimally invasive surgery has shown efficacy in the treatment of this disease and is currently considered the gold standard treatment.

Case Description: This study reports an 11-year-old female patient who was diagnosed with a splenic cyst $10 \mathrm{~cm}$ in diameter. A sonographic scan showed a giant splenic cyst $(10 \times 8.8 \times 7.6 \mathrm{~cm})$. After diagnosis, the patient was completely asymptomatic and underwent periodic sonograms, which showed the lesion to be of constant size. This finding was confirmed by a computed tomographic scan of the abdomen. Then, the patient developed recurrent episodes of pain in the left upper quadrant. Three low-friction 3-mm minilaparoscopic trocars and an 11-mm port in the umbilical region for the insertion of the optics were used in this procedure. The cyst was punctured and its contents completely aspirated. It was then resected carefully by electrocautery in its margins, preserving as much splenic tissue as possible.
\end{abstract}

Conclusion: The minilaparoscopic approach is a safe and effective technique for this procedure.

Key Words: Minilaparoscopy, Splenic cyst.

\footnotetext{
Citation Carvalho GL, Lima DL, Silva FW, Belarmino de Góes GH. Giant nonparasitic spleen cyst treated by minilaparoscopy. CRSLS e2017.00030. DOI: 10.4293/CRSLS.2017.00030.

Copyright (c) 2017 by SLS, Society of Laparoendoscopic Surgeons. This is an open-access article distributed under the terms of the Creative Commons Attribution-Noncommercial-ShareAlike 3.0 Unported license, which permits unrestricted noncommercial use, distribution, and reproduction in any medium, provided the original author and source are credited.

Disclosures: Dr. Carvalho is a consultant, without financial interest, to Karl Storz Endoscopy, São Paulo, Brazil, for the development of minilaparoscopic instruments. The other authors declare no conflicts of interest.

Address correspondence to: Gustavo Lopes de Carvalho, MD, PhD, Avenida Boa Viagem 5526B Apt. 1902, Recife, PE CEP: 51030-000, Brazil. Telephone +55 81 99971-9698, Fax: +55 81 2129-1910, E-mail: glcmd1@gmail.com
}

\section{INTRODUCTION}

Nonparasitic splenic cyst (NPSC) is a rare disease of the spleen and is categorized as a true or pseudocyst. Although they are more common in young adults (20-30 years old), they can also occur during childhood. ${ }^{1,2}$ True cysts have an epithelial lining and a congenital or neoplastic etiology. Pseudocysts are usually ( $75 \%$ of cases) a consequence of a splenic posttraumatic hematoma. ${ }^{3}$

Normally, splenic cyst is asymptomatic, and the diagnosis is incidental to abdominal imaging, particularly ultrasonography or computed tomography (CT). When a splenic cyst is present, the most common signs and symptoms are pain in the left upper quadrant, splenomegaly, or presence of a mass in the left superior quadrant. There may also be symptoms associated with the compression of adjacent organs, such as the lungs and stomach, causing pleuritic pain in the left hemithorax, nausea, and vomiting. If the cyst ruptures, there is an increased chance of developing an acute abdomen. ${ }^{4}$

Surgical treatment is indicated for a symptomatic cyst or one with a diameter $>5 \mathrm{~cm}$ (even if asymptomatic) because of the increased risk of bleeding, rupture, and in- 
fection. ${ }^{5}$ Traditionally, the management of NPSC would be partial or total splenectomy by laparotomy; however, minimally invasive surgery has shown efficacy in the treatment of this disease and is currently considered the gold standard treatment. 6,7 Because of the importance of the spleen in the immune system (especially in pediatric patients) and to prevent thrombocytosis and postoperative infections, alternative treatments have been developed to preserve more splenic tissue. These include marsupialization, partial splenectomy, partial cystectomy, and dissection of the cyst capsule. ${ }^{8}$

\section{CASE REPORT}

This study reports an 11-year-old female who was diagnosed with a splenic cyst $10 \mathrm{~cm}$ in diameter. The diagnosis was made 6 months earlier by a sonogram performed after a traumatic episode. The scan showed a giant splenic cyst $(10 \times 8.8 \times 7.6 \mathrm{~cm})$; the patient did not report any symptoms during that time. Since then, the patient has undergone periodic ultrasonography, which showed a constant size of the lesion. This finding was confirmed by a CT scan of the abdomen (Figure 1). The patient developed recurrent episodes of pain in the left upper quadrant. A minilaparoscopic approach was chosen.

\section{Surgical Description}

Surgery was performed with the patient in the right lateral position. Three low-friction 3-mm trocars and one 11-mm trocar were used in conventional $10-\mathrm{mm} 30^{\circ}$ laparoscopic optics through the umbilicus. Pneumoperitoneum was created by applying the open technique under direct vi-

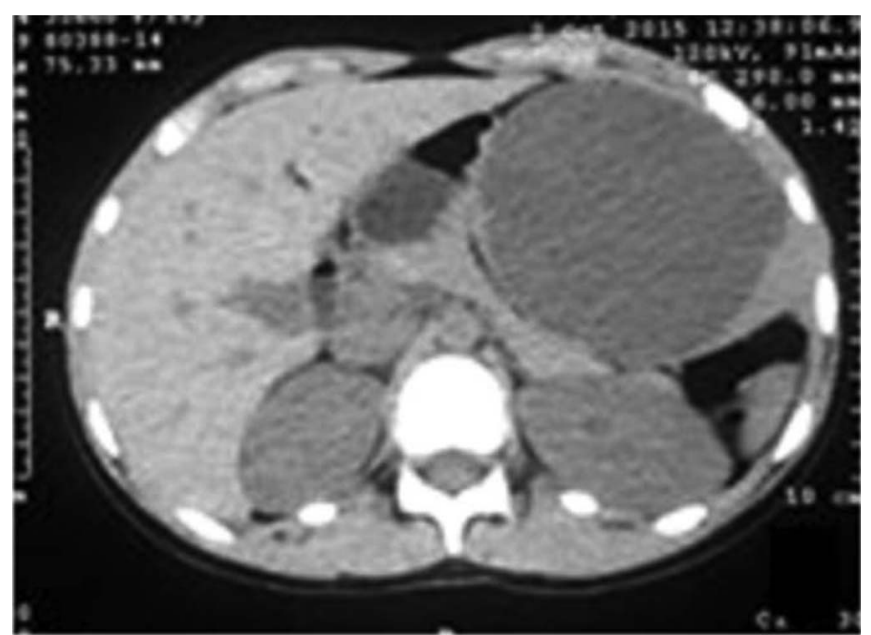

Figure 1. CT of the abdomen showing splenic cyst of hypodense appearance. sion. The setup of the surgical team, as well as the positioning of the trocars, followed the standard approach for the spleen (Figure 2).

The procedure started with a cyst puncture through an irrigation-aspiration cannula to empty the contents of the cyst completely (Figure 3). After the cyst was emptied, the fragility of its wall, which could be damaged in a trauma, became visible.

Following the precepts of spleen-sparing techniques, we chose to unroof the cyst (Figure 4), to save as much splenic tissue as possible. For this purpose, electrocautery was performed along the cyst edges. This procedure is essential to achieving a good surgical outcome because it allows the removal of the cyst capsule, and it prevents the epithelization of the edges and, therefore, the recurrence of the cyst.

After the cyst was unroofed, the observation of the cyst interior showed the tracery aspect formed by the fibrotic content (Figure 5). This area is quite crumbly and usually needs to be cauterized to control the bleeding. It is important to perform hemostasis with extreme care and to use an irrigation and aspiration cannula continuously, to catch any bleeding.

The capsule of the cyst was removed through an 11-mm umbilical portal. Then, a new hemostasis review was conducted. The total surgery time was 54 minutes. The patient had no major blood loss and no further complications and was discharged on the same day. A histopathologic study showed an NPSC.

\section{DISCUSSION}

Splenic cyst was first described by Berthelot in 1790 and NPSC in $1829.9^{9}$ Since then, more than 700 cases of NPSC have been described in the literature. McClure and Altemeier $^{10}$ developed the most classic categorization of splenic cyst, which was a modification of Fowler's classification. ${ }^{11}$ According to the classification system of McClure and Altemeier, splenic cysts are divided into true (or primary) cysts and pseudo (or secondary) cysts. According to their etiology, primary cysts can be parasitic, inflammatory, neoplastic, or congenital. Pseudocysts are categorized as traumatic, degenerative, or inflammatory. ${ }^{12}$

Traditionally, splenic cyst is asymptomatic; however, the most common signs and symptoms of its existence are the presence of a mass in the upper left quadrant and the occurrence of pain due to the length of the capsule or the compression of adjacent organs. Satiety has also been reported. ${ }^{13}$ Rare complications, such as bleeding, infection, 

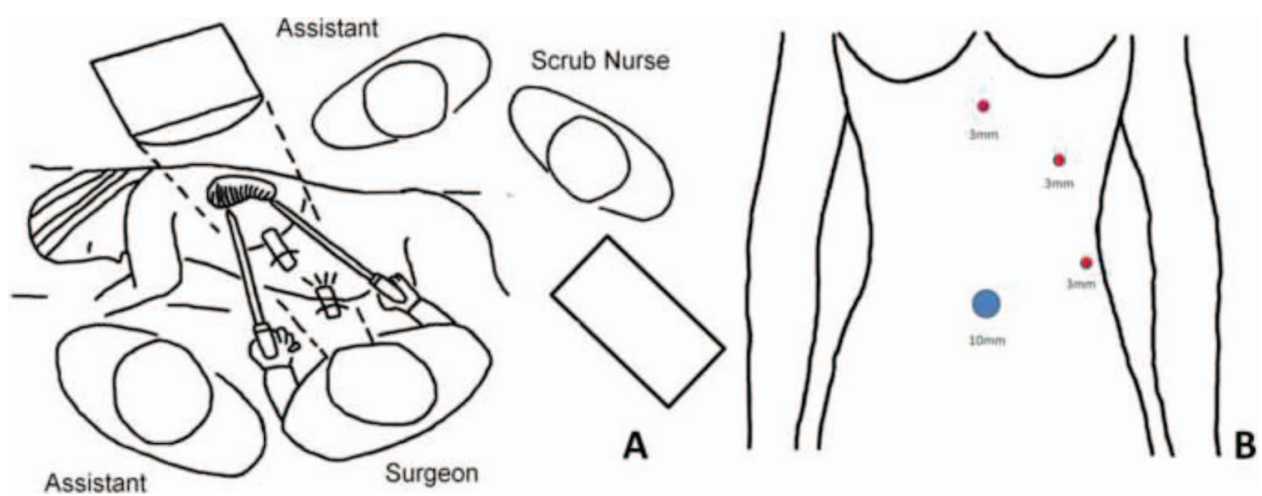

Figure 2. (A) Organization of the operating room and surgical team. (B) Patient positioning showing sites of the ports: three 3-mm low-friction trocars and one 11- $\mathrm{mm}$ in the umbilicus for the use of a 10-mm conventional laparoscopy scope.
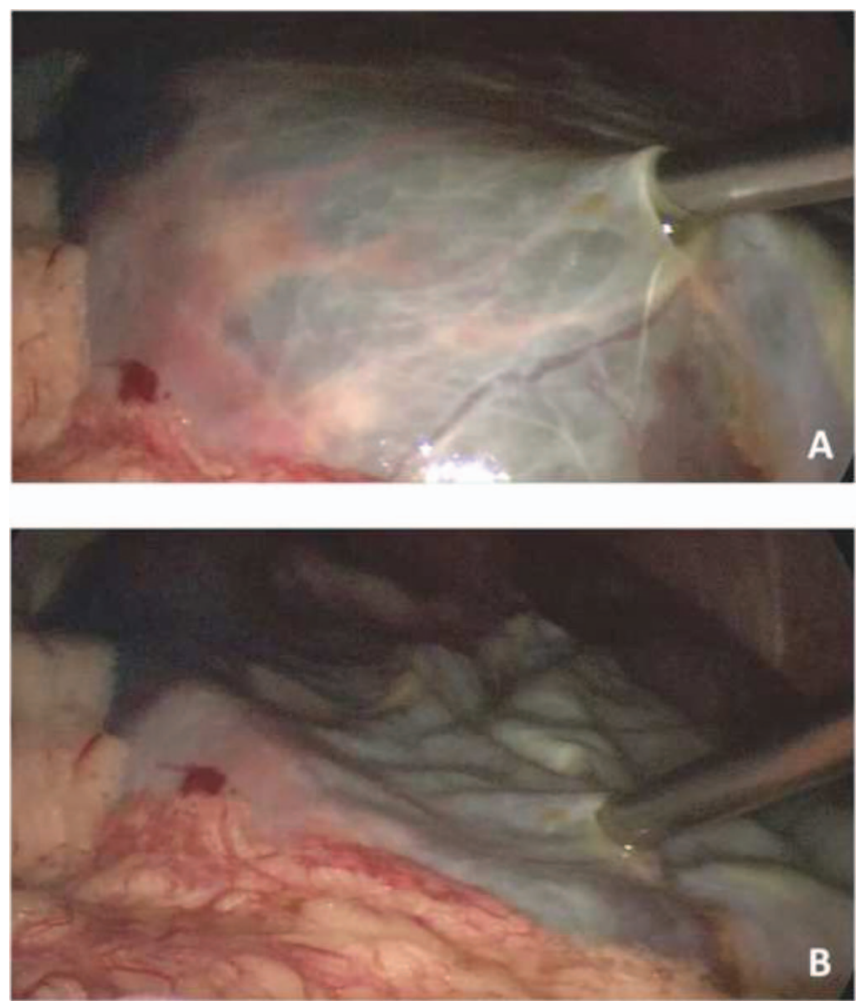

Figure 3. (A) Cyst-drilling with irrigation-aspiration cannula for complete emptying of its content. (B) Friable aspect of the cystic capsule that can be ruptured in possible future trauma.

or cyst rupture, are associated with the increased presence of clinical signs and symptoms.

The main imaging tests that are helpful in the diagnosis of splenic cyst are ultrasonography and CT. A simple cyst complicates the sonographic diagnosis, unless classic features are present, such as an anechoic image and thin wall with enhancement of structures located pos-
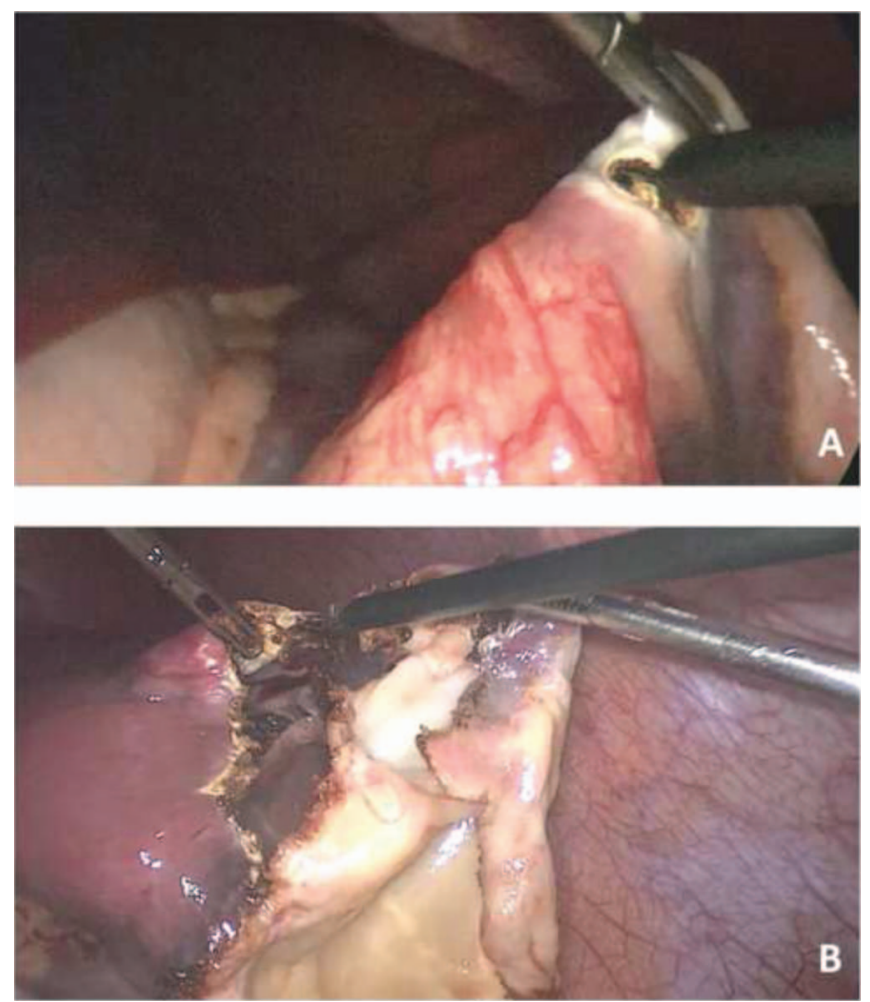

Figure 4. (A) Beginning of cyst decapsulation by electrocautery. (B) End of decapsulation.

terior to the cyst. Another feature that facilitates the sonographic diagnosis is that splenic cyst is usually completely inside the spleen. Complications, such as infection and hemorrhage, are associated with debris and echogenic content within the cyst, as well as thickening of the cyst capsule. A brightness in the center due to wall calcification is more common in secondary cysts than in primary ones. ${ }^{14}$ 

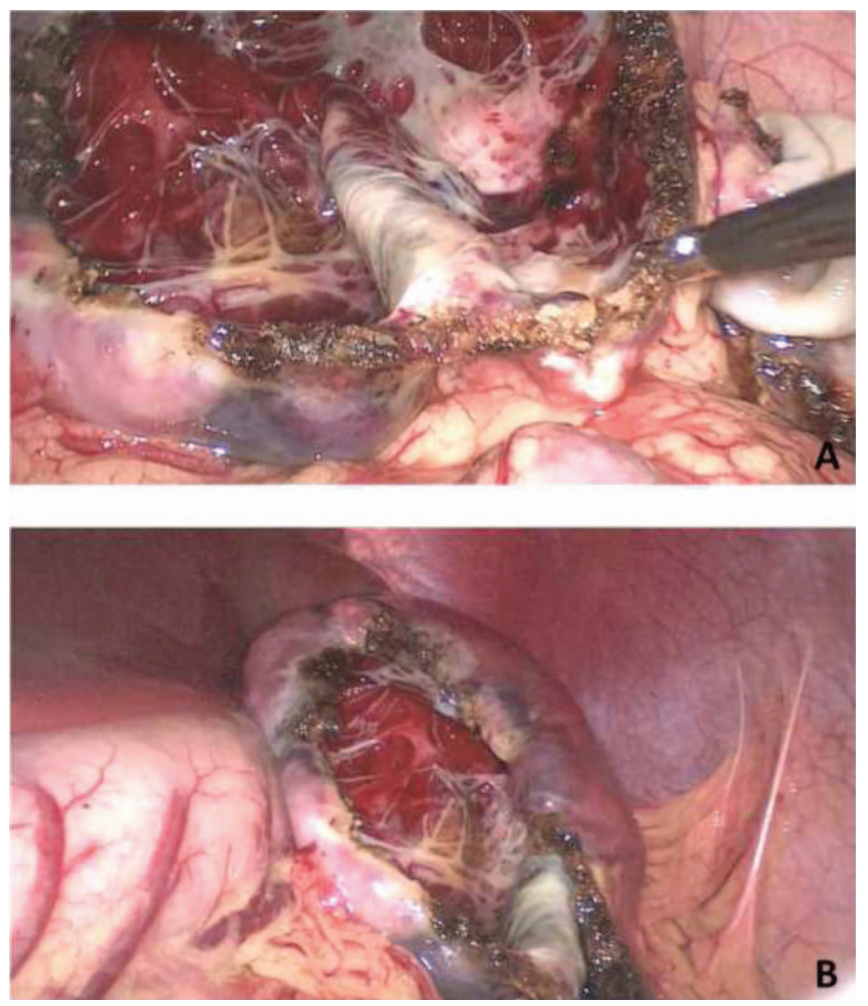

Figure 5. (A) Cauterization of the cyst edges to prevent relapse and observation of tracery formed by fibrotic tissue in its interior. (B) Final aspect of the spleen after resection of the cyst.

In CT, the images of true cysts and pseudocysts are similar in anechoic appearance. ${ }^{15}$ This imaging method has the advantage of precision in determining the size, position, and type of the cyst content. However, CT does not differentiate the origin of the cyst. ${ }^{13}$

For asymptomatic and small cysts (diameter $<5 \mathrm{~cm}$ ), the current management is conservative treatment, with periodic ultrasonographic evaluation every 6 months. If the cyst does not increase in size, the monitoring becomes annual. However, if the cyst increases in size or becomes symptomatic, a surgical approach should be considered. ${ }^{16}$ When evaluating large cysts (diameter $>5 \mathrm{~cm}$ ), surgical treatment is more appropriate because of the high risk of complications, such as rupture or bleeding. For symptomatic cysts, regardless of size, surgical intervention should also be considered.

The first surgical treatment of a splenic cyst was performed in 1867, when Jules Pean ${ }^{17}$ attempted to do a cystectomy. However, because of the high risk of bleeding, the procedure was converted into a total splenectomy, which was thus established as the traditional treatment approach to splenic cysts, regardless of their etiology. Later, the recognition of the importance of the spleen to the immune system (mainly in pediatric patients) led to an increased search for alternatives to preserve the maximum possible splenic tissue, referred to as spleen-sparing techniques. Among these techniques are aspiration of the cyst content, marsupialization, removal of the cyst capsule, and partial and total splenectomy.

The indications for splenectomy is a large cyst, called an internal cyst, that is completely surrounded by the parenchyma or a cyst located in the hilum. When there are multiple cysts, a total spleen resection is also indicated. The approach may be laparotomy or laparoscopy, with all the wellknown advantages of minimally invasive surgery, such as shorter hospital stay and less pain in the postoperative period. ${ }^{18}$

Another effective option that has been increasingly used is partial splenectomy, an alternative approach primarily for pediatric patients. In this specific group of patients, the preservation of at least $25 \%$ of splenic tissue is sufficient and extremely important to protect the patient from pneumococcal bacteremia. ${ }^{13}$ Marsupialization, which is the creation of an opening in the cyst wall for the purpose of drainage, is another option; however, this method is not currently recommended because of the high rate of recurrence of the cyst. ${ }^{19}$

The removal of the cyst capsule, a technique that consists of resecting the cyst and the contiguous splenic parenchyma, ensures that no cyst remains in the spleen and thus leads to a low rate of cyst recurrence. ${ }^{20}$ This method can be applied to both pseudocyst and epidermoid cyst. Being located in the anterior or on the surface of the spleen is an important characteristic of the cyst when a minimally invasive technique is considered. ${ }^{21}$

Compared with conventional laparoscopy, minilaparoscopy has the advantages of causing less trauma to the abdominal wall and, consequently, less postoperative pain, requiring shorter hospital stay, providing better visualization of the surgical field, and enabling more precise movements. Firme et $\mathrm{al}^{22}$ showed that for gross grasping tasks, the conventional 5-mm instruments are better, but for more precise and complex movements, the low-friction 3-mm instruments performed best. These conclusions lead to the possibility of preserving more splenic tissue, particularly in the present case..$^{23-26}$ Minilaparoscopy has been shown to be safe and effective for many types of surgery, such as cholecystectomy and hernia repair. 27,28 Other more complex procedures were also described. ${ }^{29}$

There are no reports in the literature about the resection of splenic cysts by minilaparoscopy. However, minilaparoscopy has been described for splenectomy. ${ }^{30}$ 
This case report describes the successful minilaparoscopic treatment of a giant NPSC in a pediatric patient. Although there is no consensus on the ideal approach in this case, the minilaparoscopic decapsulation of the cyst was a safe and effective method, and its advantages were useful for the procedure performed.

\section{References:}

1. Mielle V, Galluzo M, Cortese A, et al. Diagnostic imaging of splenic cysts in children. Radiol Med. 1998;95:62-65.

2. Tsakayannis DE, Mitchell K, Kozakewich HP, et al. Splenic preservation in the management of splenic epidermoid cysts in children. J Pediatr Surg. 1995;30:1468-1470.

3. Andrews MW. Ultrasound of the spleen. World J Surg. 2000; 24:183-187.

4. Liew SH, Clements WD, Wilson BG. Splenic conservation in the management of large splenic cysts: case report and literature review. J R Coll Surg Edinb. 1997;42:135-137.

5. Walz MK, Metz KA, Sastry M, et al. Benign mesothelial splenic cyst may cause high serum concentration of CA 19-9. Eur J Surg. 1994;160:389-391.

6. Rosin D, Brasesco O, Rosenthal RJ. Laparoscopic splenectomy: new techniques and indications. Chirurg. 2001;72:368-377.

7. Yagi S, Isaji S, Iida T, et al. Laparoscopic splenectomy for a huge splenic cyst without preoperative drainage: report of a case. Surg Laparosc Endosc Percutan Tech. 2003;13:397-400.

8. Balzan SM, Riedner CE, Santos LM, et al. Posttraumatic splenic cysts and partial splenectomy: report of a case. Surg Today. 2001;31:262-265.

9. Andral G. Précis d'anatomie pathologique. Paris: Gabon, 1829.

10. McClure RD, Altemeier A. Cyst of the spleen. Ann Surg. 1942;116:98-102.

11. Fowler RH. Cysts of the spleen: a pathological and surgical study. Am Surg. 1913;57:658-690.

12. Radakovich M. Epidermoid cyst of the spleen. Ann Surg. 1950;131:268-276.

13. Torres OJM, Lucena LC, Matos Junior EM, et al. Laparoscopic treatment of a benign splenic cyst. Rev Bras Videocir. 2006;4: 118-121.

14. Chen MJ, Huang MJ, Chang WH, et al. Ultrasonography of splenic abnormalities. World J Gastroenterol. 2005;11:4061-4066.

15. Gaetke-Udager K, Wasnik AP, Kaza RK, et al. Multimodality imaging of splenic lesions and the role of non-vascular, imageguided intervention. Abdom Imaging. 2014;39:570-587.

16. Sinha CK, Agrawal M. Nonparasitic splenic cysts in children: current status. Surgeon. 2011;9:49-53.
17. Pean J. Splenotomy (ablation of a splenic cyst and complete extirpation of hypertrophied spleen); recovery! L'union Med. 1867;4: 340-77 [Translated by Harold Ellis in: Clio chirurgia, part IV. Early cases of splenectomy for splenic disease: 39-42].

18. Kaiwa Y, Kurokawa Y, Namiki K, et al. Laparoscopic partial splenectomies for true splenic cysts: a report of two cases. Surg Endosc. 2000;14:865.

19. Sullivan CA, Konefal SH. Epidermoid cyst of the spleen successfully treated by marsupialization. Clin Pediatr. 1987;26:203-205.

20. Morgenstern L, Shapiro SJ. Partial splenectomy for nonparasitic splenic cysts. Am J Surg. 1980;139:278-281.

21. Calligaris L, Bortul M. Laparoscopic treatment of a nonparasitic splenic cyst: Case Report. J Laparosc Surg. 1996;6:431-433.

22. Firme WA, Carvalho GL, Lima DL, et al. Low-friction minilaparoscopy outperforms regular 5-mm and 3-mm instruments for precise tasks. JSLS. 2015;Jul-Sep;19(3): e2015.00067. DOI: 10.4293/JSLS.2015.00067

23. Carvalho GL, Melani AG, Veo CAR, et al. New low friction adapter for using minilaparoscopic instruments with transanal endoscopic microsurgery (TEM) improves visualization and dexterity (abstract). Surg Endosc. 2013;27:S164.

24. Araujo SEA, Mendes CRS, Carvalho GL, et al. Surgeons' perceptions of transanal endoscopic microsurgery using minilaparoscopic instruments in a simulator: the thinner the better. Surg Endosc. 2015;29:2331-2338.

25. Passos Jr GO, Lima DL, Silva FW, et al. Surgeons' perceptions in relation to the minilaparoscopic instruments in surgical knots construction (abstract). Surg Endosc. 2014;28(suppl):S333.

26. Carvalho GL, Sales AC, Silva JS, et al. Are minilaparoscopic (needlescopic) trocars of $2 \mathrm{~mm}$ and $3 \mathrm{~mm}$ without valve and sealing membrane a viable option (abstract)? Surg Endosc. 2011; 25(suppl):S351.

27. Carvalho GL, Silva FW, Silva JS, et al. Needlescopic clipless cholecystectomy as an efficient, safe, and cost-effective alternative with diminutive scars: the first 1000 cases. Surg Laparosc Endosc Percutan Tech. 200919:368-372.

28. Malcher F, Cavazzola LT, Carvalho GL, et al. Minilaparoscopy for inguinal hernia repair. JSLS. 2016;Oct-Dec;20(4): e2016.00066 DOI: 10.4293/JSLS.2016.00066.

29. Carvalho GL, Abreu GFS, Lima DL, et al. Type IV Mirizzi syndrome treated with hepaticoduodenostomy and minilaparoscopy. CRSLS. 2016:e2016.00057. DOI: 10.4293/CRSLS. 2016.00057.

30. Backus CL, Park AE, Matthews BD, Heniford BT. Mini-laparoscopic splenectomy. J Laparoendosc Adv Surg Tech A. 2000; 10:259-262. 